\title{
Estresse inicial por baixo oxigênio seguido do armazenamento em atmosfera controlada de maçãs 'Royal Gala'
}

\author{
Initial low oxygen stress followed by storage in controlled atmosphere of 'Royal \\ Gala' apples
}

\author{
Vanderlei Both $^{2 *}$, Auri Brackmann ${ }^{3}$, Anderson Weber ${ }^{2}$, Rogerio de Oliveira Anese ${ }^{2}$ e Fabio Rodrigo Thewes ${ }^{2}$
}

\begin{abstract}
RESUMO - O objetivo do presente trabalho foi avaliar a aplicação de estresse inicial por baixo oxigênio e 1metilciclopropeno (1-MCP) sobre a manutenção de qualidade de maçãs 'Royal Gala' armazenadas em atmosfera controlada (AC). Para tanto, um lote com 50\% dos frutos foi tratado com 1-MCP (625 ppb) e destes, a metade, juntamente com a metade daqueles sem aplicação de 1-MCP, foram submetidos a um estresse por baixo oxigênio ( $0,3 \mathrm{kPa}$ por sete dias), antes de serem armazenados por sete meses, a $0,5{ }^{\circ} \mathrm{C}$ e nas seguintes condições de $\mathrm{AC}: 1,2 \mathrm{kPa} \mathrm{O}_{2}+2,0 \mathrm{kPa} \mathrm{CO} ; 1,0 \mathrm{kPa} \mathrm{O}_{2}$

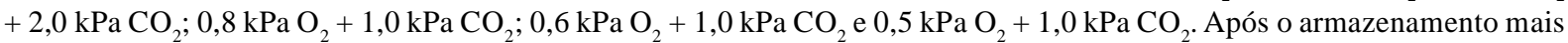
sete dias de exposição a $20{ }^{\circ} \mathrm{C}$ foram realizadas análises de qualidade nos frutos. Os resultados evidenciam que o estresse inicial por baixo $\mathrm{O}_{2}$ não é eficiente em manter a qualidade, inclusive aumentando a ocorrência de distúrbios fisiológicos e podridões. Não houve grande diferença na eficiência das condições de AC utilizadas neste trabalho sobre a conservação da qualidade dos frutos. A aplicação de 1-MCP não melhorou a preservação da qualidade dos frutos armazenados em ultrabaixo $\mathrm{O}_{2}$, como verificado nas menores pressões parciais $(<1,0 \mathrm{kPa})$ utilizadas no presente trabalho.
\end{abstract}

Palavras-chave: Malus domestica. Etileno. 1-metilciclopropeno (1-MCP).

\begin{abstract}
The aim of this work was to evaluate the application of initial low oxygen stress and 1-methylcyclopropene (1-MCP) on quality maintenance of Royal Gala apples, when stored in a controlled atmosphere (CA). In order to do this, a lot of $50 \%$ of the fruit was treated with $1-\mathrm{MCP}(625 \mathrm{ppb})$ and one half of these, together with half of the fruit which did not receive the application of 1-MCP, were subjected to low oxygen stress ( $0.3 \mathrm{kPa}$ for seven days) before being stored for seven months at $0.5{ }^{\circ} \mathrm{C}$ under the following CA conditions: $1.2 \mathrm{kPa} \mathrm{O}_{2}+2.0 \mathrm{kPa} \mathrm{CO}_{2} ; 1.0 \mathrm{kPa} \mathrm{O}+2.0 \mathrm{kPa}$ $\mathrm{CO}_{2} ; 0.8 \mathrm{kPa} \mathrm{O}_{2}+1.0 \mathrm{kPaCO}_{2} ; 0.6 \mathrm{kPa} \mathrm{O}+1.0 \mathrm{kPa} \mathrm{CO}_{2}$ e $0.5 \mathrm{kPa} \mathrm{O}_{2}+1.0 \mathrm{kPa} \mathrm{CO}$. After storage, and following a further seven days at $20^{\circ} \mathrm{C}$, analyses of fruit quality were carried out. The results show that initial low oxygen stress is not effective in maintaining quality, beyond increasing the occurrence of physiological disorders and decay. There was no big difference in the efficiency of the CA conditions used in this study on the conservation of fruit quality. The application of 1-MCP did not improve quality maintenance in fruit stored under ultralow oxygen, as seen at the lowest partial pressures $(<1.0 \mathrm{kPa})$ used in this work.
\end{abstract}

Key words: Malus domestica. Ethylene. 1-methylcyclopropene (1-MCP).

\footnotetext{
*Autor para correspondência

'Recebido para publicação em 02/08/2012; aprovado em 08/05/2014

Parte da Dissertação do primeiro autor apresentada ao Programa de Pós-Graduação em Agronomia da Universidade Federal de Santa Maria ${ }^{2}$ Programa de Pós-graduação em Agronomia, Departamento de Fitotecnia, Centro de Ciências Rurais, Universidade Federal de Santa Maria/ UFSM, Av. Roraima, n 1000, Santa Maria-RS, Brasil, 97.105-900, vanderleiboth@yahoo.com.br, anweba@yahoo.com.br, rogerio_anese@ yahoo.com.br, fthewes@yahoo.com.br

${ }^{3}$ Departamento de Fitotecnia, Centro de Ciências Rurais, Universidade Federal de Santa Maria/UFSM, Santa Maria-RS, Brasil, auribrackmann @ gmail.com
} 


\section{INTRODUÇÃO}

A maçã 'Royal Gala', mutação espontânea da 'Gala', foi descoberta na Nova Zelândia em 1971 e introduzida comercialmente em 1974. Desde então, vem tendo grande aceitação pelo mercado, por produzir frutos mais uniformemente coloridos que a 'Gala' (CAMILO; DENARDI, 2006). A colheita se concentra no mês de fevereiro e, portanto, necessita ser eficientemente armazenada para ser ofertada durante o ano todo.

Uma das técnicas mais utilizadas no armazenamento de maçãs é a atmosfera controlada (AC), em que além da diminuição da temperatura, também há redução na pressão parcial do $\mathrm{O}_{2}$ e aumento do $\mathrm{CO}_{2}$ nas câmaras de armazenamento. As pressões parciais recomendadas para o armazenamento de maçãs 'Royal Gala' para o Sul do Brasil são de 1,0 $\mathrm{kPa}$ de $\mathrm{O}_{2}$ e $2,5 \mathrm{kPa}$ de $\mathrm{CO}_{2}$ (BRACKMANN et al., 2008). No entanto, mesmo em AC ocorrem perdas durante um armazenamento prolongado, especialmente com a ocorrência de distúrbios fisiológicos e podridões (WATKINS, 2010).

Desta forma, técnicas auxiliares à $\mathrm{AC}$ estão sendo estudadas para manter a qualidade dos frutos durante o armazenamento. Dentre estas, se destaca a aplicação do composto 1-metilciclopropeno (1-MCP), que se liga de forma irreversível aos receptores de etileno na membrana do retículo endoplasmático das células, impedindo a ligação do etileno ao receptor. Assim, a aplicação do 1MCP inibe o estímulo fisiológico e a transdução de sinal desencadeada pelo etileno, reduzindo o amadurecimento (BLANKENSHIP; DOLE, 2003) e ocorrência de distúrbios (DELONG, PRANGE; HARRISON, 2004).

Além do 1-MCP, outra técnica pesquisada, especialmente para o controle de escaldadura de maçãs suscetíveis, é a aplicação de um estresse inicial por baixo oxigênio (ILOS - Initial Low Oxygen Stress) nos frutos, antes do armazenamento em AC (LAU, 1997; MATTÈ et al., 2005; WANG; DILLEY, 2000; ZANELLA, 2003). Esta técnica consiste no armazenamento, por um determinado período (até duas semanas), em uma atmosfera contendo $\leq 0,5 \mathrm{kPa}$ de $\mathrm{O}_{2}$ (EKMAN; GOLDING; McGLASSON, 2005). No entanto, além do benefício para o controle da escaldadura, também foi constatado menor perda de firmeza de polpa (MATTÈ et al., 2005; WANG; DILLEY, 2000) e maior acidez nos frutos submetidos a esta técnica (MATTÈ et al., 2005). De acordo com Pesis et al. (2010), a aplicação de um estresse inicial, com fluxo de $\mathrm{N}_{2}$, manteve a firmeza de polpa de maçãs 'Granny Smith' de forma similar à aplicação de 1-MCP após quatro meses de armazenamento na temperatura de $0{ }^{\circ} \mathrm{C}$.

A aplicação de estresse inicial por baixo oxigênio provoca um período de anaerobiose nos frutos, com produção de etanol e acetaldeído que, em pequenas concentrações, podem ser benéficos para manutenção da qualidade dos mesmos durante o armazenamento. De acordo com Lara et al. (2011), condições de anaerobiose podem ocorrer naturalmente durante o amadurecimento em partes internas da polpa dos frutos. Dessa forma, a aplicação de estresse por baixo oxigênio induz a síntese das enzimas piruvato descarboxilase (PDC) e álcool desidrogenase (ADH), que ajudam a destoxificar o acetaldeído normalmente produzido durante o amadurecimento dos frutos (POLENTA; BUDDE; MURRAY, 2005).

Tendo em vista que a aplicação de estresse inicial por baixo $\mathrm{O}_{2}$ ainda não foi estudada para as cultivares e condições brasileiras, o presente trabalho tem por objetivo investigar o uso desta técnica associada ao armazenamento em diferentes condições de AC, bem como compará-la com a aplicação do 1-MCP, sobre a manutenção da qualidade de maçãs 'Royal Gala'.

\section{MATERIAL E MÉTODOS}

A colheita dos frutos foi realizada em um pomar comercial no município de Vacaria, Rio Grande do Sul, no dia 12 de fevereiro de 2010, momento em que apresentavam firmeza de polpa de 68,6 Newtons, índice iodoamido 8,53 (escala de 1 a 10), acidez de 4,17 meq $100 \mathrm{~mL}^{-1}$, 10,7 ${ }^{\circ}$ Brix de Sólidos Solúveis Totais (SST), atividade da enzima ACC oxidase $67,8 \mathrm{~nL} \mathrm{C}_{2} \mathrm{H}_{4} \mathrm{~g}^{-1} \mathrm{~h}^{-1}$ e produção de etileno de $0,408 \mu \mathrm{L} \mathrm{C}_{2} \mathrm{H}_{4} \mathrm{~kg}^{-1} \mathrm{~h}^{-1}$.

Para o armazenamento dos frutos foram utilizadas cinco condições de atmosfera controlada (AC) $(1,2 \mathrm{kPa}$ $\mathrm{O}_{2}+2,0 \mathrm{kPaCO} ; 1,0 \mathrm{kPa} \mathrm{O}_{2}+2,0 \mathrm{kPa} \mathrm{CO} ; 0,8 \mathrm{kPa} \mathrm{O}$ $+1,0 \mathrm{kPa} \mathrm{CO} ; 0,6 \mathrm{kPa} \mathrm{O}_{2}+1,0 \mathrm{kPa} \mathrm{CO}_{2}$ e $0,5 \mathrm{kPa} \mathrm{O}_{2}$ $+1,0 \mathrm{kPa} \mathrm{CO}$ ), combinadas com aplicação de 1-MCP (com ou sem 1-MCP) e estresse inicial por baixo $\mathrm{O}_{2}$ (com ou sem estresse). Assim, em cada minicâmara de $\mathrm{AC}$, foram armazenados frutos submetidos a quatro condições (sem estresse e sem 1-MCP; com estresse e sem 1-MCP; sem estresse e com 1-MCP e com estresse e com 1-MCP), resultando em 20 tratamentos (4 níveis do fator estresse/1-MCP x 5 níveis de AC). Primeiramente foi aplicado 1-MCP nos frutos de 10 tratamentos. Em seguida, cinco destes tratamentos, juntamente com outros cinco tratamentos em que não foi aplicado 1-MCP, foram colocados, durante uma semana, em minicâmaras experimentais de $0,4 \mathrm{~m}^{3}$, com pressão parcial de $0,3 \mathrm{kPa}$ de $\mathrm{O}_{2}$ e $1,0 \mathrm{kPa} \mathrm{CO}$ (estresse inicial por baixo $\mathrm{O}_{2}$ ). Os frutos dos outros 10 tratamentos foram acondicionados em minicâmaras com as concentrações de gases pré-determinadas para cada tratamento. Após uma semana de estresse inicial por baixo $\mathrm{O}_{2}$, esses frutos foram acondicionados com os demais, 
dentro das minicâmaras, de acordo com as pressões parciais de gases previstas para cada tratamento.

As condições de AC foram obtidas dentro de cada minicâmara experimental de $0,4 \mathrm{~m}^{3}$, que permaneceram dentro de uma câmara frigorífica maior, onde a temperatura de armazenamento foi mantida em $0,5{ }^{\circ} \mathrm{C}( \pm 0,1)$. A temperatura foi controlada por meio de um termômetro eletrônico e monitorada diariamente com um termômetro de mercúrio de alta precisão, com o bulbo inserido na polpa de um fruto. A umidade relativa no interior das minicâmaras foi mantida em $96 \%( \pm 1,0)$.

Para a instalação da atmosfera controlada, a pressão parcial de $\mathrm{O}_{2}$ foi obtida pela diluição deste gás nas minicâmaras por meio da varredura com nitrogênio, proveniente de um gerador de $\mathrm{N}_{2}$ que utiliza o princípio Pressure Swing Adsorption (PSA). A pressão parcial de $\mathrm{CO}_{2}$ foi obtida mediante a injeção deste gás nas minicâmaras, proveniente de um cilindro de alta pressão. A concentração de gases nas minicâmaras foi monitorada diariamente com o auxílio de um analisador de gases da marca Schelle ${ }^{\circledR}$. Em função da respiração dos frutos houve consumo de $\mathrm{O}_{2}$ e produção de $\mathrm{CO}_{2}$. A reposição do $\mathrm{O}_{2}$ foi realizada pela injeção de ar atmosférico e a absorção do $\mathrm{CO}_{2}$ ocorreu por meio da circulação do ar das minicâmaras por uma solução de hidróxido de potássio (40\%).

Para a aplicação do 1-MCP utilizou-se o produto SmartFresh $^{\circledR}$, na concentração de 625 ppb. O produto foi solubilizado em $20 \mathrm{~mL}$ de água destilada, em um frasco de vidro fechado hermeticamente. Em seguida, foi transferido para uma placa de Petri, no interior das minicâmaras em que estavam os frutos, que foram imediatamente fechadas. Os frutos ficaram expostos ao produto por 24 horas, na temperatura de $0,5{ }^{\circ} \mathrm{C}$. Após este período, o ar das minicâmaras foi circulado com ar externo, antes de serem abertas e os frutos retirados e acondicionados com os demais, não tratados.

Após sete meses de armazenamento em AC os frutos foram retirados das minicâmaras e expostos durante sete dias a $20{ }^{\circ} \mathrm{C}$ e em condição normóxica, para simular o período de vida de prateleira, antes das análises de qualidade e maturação. Foram analisadas as seguintes variáveis: a) Incidência de podridões: pela contagem dos frutos que apresentaram lesões com diâmetro superior a $5 \mathrm{~mm}$, característica de ataque de patógenos e expresso em porcentagem; b) Distúrbios fisiológicos: foram realizados cortes transversais na região equatorial dos frutos, em que foram avaliados visualmente quanto ao escurecimento da polpa, sintoma característico de degenerescência e polpa seca e sem suculência, sintoma de polpa farinácea; c) Frutos sadios: total de frutos de que não apresentavam nenhum dano, estando aptos para a comercialização e consumo; d) Firmeza da polpa: após a retirada de parte da epiderme, os frutos foram perfurados em lados opostos, na região equatorial, com um penetrômetro da marca Effegi, com ponteira de $11 \mathrm{~mm}$, com os valores sendo expressos em Newton (N); e) Acidez titulável: determinada pela titulação, com $\mathrm{NaOH} 0,1 \mathrm{~N}$, de uma solução contendo $10 \mathrm{~mL}$ de suco dos frutos, diluídos em $100 \mathrm{~mL}$ de água deionizada, até atingir pH 8,1. Os valores foram expressos em meq $100 \mathrm{~mL}^{-1}$; f) Atividade da ACC oxidase: de acordo com a metodologia proposta por Bufler (1986), foram retirados aproximadamente $3 \mathrm{~g}$ da epiderme dos frutos de cada unidade experimental e incubadas numa solução contendo $0,1 \mathrm{mM}$ de ACC em $10 \mathrm{mM}$ do tampão MES (ácido 2 (N-morfolino) etanossulfônico) em pH 6,0. Após 30 minutos, as amostras foram acondicionadas em seringas herméticas de $50 \mathrm{~mL}$, nas quais foram adicionados $2 \%$ de $\mathrm{CO}_{2}$. Decorridos mais 30 minutos, a concentração de etileno presente nas seringas foi determinada, por cromatografia, com os dados expressos em $\mathrm{nL} \mathrm{C}_{2} \mathrm{H}_{4} \mathrm{~g}^{-1} \mathrm{~h}^{-1} ; \mathrm{g}$ ) Produção de etileno: aproximadamente $1.500 \mathrm{~g}$ de frutos foram acondicionados em recipientes de vidro com volume de $5.000 \mathrm{~mL}$, fechados hermeticamente, do qual se retirou amostras de $1 \mathrm{~mL}$ de ar do headspace de cada recipiente, que foi injetado em um cromatógrafo a gás, marca Varian ${ }^{\circledR}$ modelo Star $3400 \mathrm{CX}$, equipado com um detector por ionização em chama (FID) e coluna Porapak N80/100 de dois metros de comprimento. A temperatura da coluna, injetor e detector foi de $90 ; 140$ e $200{ }^{\circ} \mathrm{C}$, respectivamente. A produção de etileno foi calculada em função da concentração deste gás presente no recipiente no momento da determinação, da massa dos frutos, do volume do espaço livre no recipiente e do tempo de fechamento, sendo expresso em $\mu \mathrm{L} \mathrm{C}_{2} \mathrm{H}_{4} \mathrm{~kg}^{-1} \mathrm{~h}^{-1}$.

Para a realização da análise estatística foi utilizado o pacote estatístico SOC (Software Científico: NTIA/EMBRAPA). Antes da análise de variância, os dados foram testados quanto à normalidade $\mathrm{e}$ aqueles que não atendiam a este pressuposto foram transformados pela fórmula arc.sen $((x+0,5) / 100)^{0,5}$. Em seguida, as médias foram comparadas pelo teste de Tukey $(p>0,05)$. Foram utilizadas quatro repetições de 25 frutos por tratamento, totalizando 100 frutos, o que é suficiente, de acordo com dados da literatura para esta cultivar de maçã, admitindo um erro de estimação de até 5\% da média (TOEBE et al., 2011).

\section{RESULTADOS E DISCUSSÃO}

Houve interação significativa apenas entre estresse inicial/1-MCP e as diferentes concentrações de AC para a variável etileno (na avaliação realizada na saída das câmaras) 
e para a acidez. O efeito da aplicação de estresse/1-MCP apenas não foi significativo para as variáveis degenerescência de polpa e etileno (sete dias a $20^{\circ} \mathrm{C}$ ). Somente as variáveis podridões, atividade da enzima ACC oxidase e etileno (saída da câmara) foram afetadas de modo significativo pelas diferentes condições de AC (Tabela 1).

No momento da instalação dos experimentos, os frutos apresentaram índice iodo-amido de 8,53 (escala de 1-10), significando que estavam em avançado estádio de maturação na colheita. No entanto, estes frutos foram adquiridos na plena colheita, em que eram colhidos para o armazenamento comercial, representando, portanto, a condição real daquele ano. O ano de 2010 foi caracterizado por ser bastante chuvoso durante o ciclo de frutificação da macieira. Como consequência, a incidência de radiação solar foi menor, comprometendo os parâmetros de qualidade dos frutos no momento da colheita, a exemplo do teor de SST e firmeza de polpa que apresentaram valores mais baixos, comparado com os valores geralmente observados para esta cultivar. $\mathrm{O}$ efeito da menor radiação solar sobre a qualidade de maçã foi reportado por Amarante, Steffens e Argenta (2011), em um experimento com tela antigranizo, constatando que plantas cobertas acumulavam 18,4\% menos radiação fotossinteticamente ativa sobre o dossel. Este fato resultou em menor firmeza de polpa, SST e aumento de índice iodo-amido nos frutos da cultivar 'Gala' no momento da colheita.

Após sete meses de armazenamento mais sete dias de exposição dos frutos a $20^{\circ} \mathrm{C}$, a condição de $1,0 \mathrm{kPa} \mathrm{O}$ $+2,0 \mathrm{kPa} \mathrm{CO}$ foi a que proporcionou a menor ocorrência de podridões, no entanto apenas diferiu estatisticamente da condição de $0,5 \mathrm{kPa} \mathrm{O}_{2}+1,0 \mathrm{kPa} \mathrm{CO}$, que apresentou
$25 \%$ de frutos com podridões, em média (Tabela 2). Com relação à aplicação de estresse inicial por baixo oxigênio, os frutos que estavam nesta condição e não receberam 1-MCP apresentaram a maior ocorrência de podridão, não diferindo estatisticamente para aqueles que receberam estresse inicial e aplicação de 1-MCP. As menores porcentagens de frutos com podridões foram observadas nos tratamentos sem aplicação de estresse inicial. Em tomates o desenvolvimento de podridões foi reduzido com a exposição dos frutos a uma condição de anoxia durante 24 horas, mas aumentou quando esta condição foi mantida durante 48 horas (FALLIK et al., 2003). Possivelmente a condição de estresse inicial e subsequente armazenamento em condições baixas de $\mathrm{O}_{2}$, utilizadas no presente trabalho, tenha sido uma condição extrema para o armazenamento dos frutos, limitando o suprimento de energia, necessária para manter a integridade das membranas e defesa contra ataques fúngicos. De acordo com Saquet, Streif e Bangerth (2003), uma das respostas das células das plantas ao armazenamento em $\mathrm{O}_{2}$ muito baixo é a indução da rota fermentativa e a consequente redução dos níveis de ATP.

$\mathrm{Na}$ avaliação da ocorrência de degenerescência de polpa, não foi observada diferença estatística entre os frutos armazenados nas diferentes condições de AC, sob estresse inicial ou aplicação de 1-MCP (Tabela 3). A presença de etileno na câmara de armazenamento acelera a senescência e proporciona maior ocorrência de degenerescência nos frutos. Dessa forma, a aplicação de 1-MCP pode reduzir a incidência de degenerescência de polpa (DELONG; PRANGE; HARRISON, 2004), o que não foi observado no presente trabalho. No entanto, pode-se observar que os demais tratamentos

Tabela 1 - Valores de F calculado e Coeficiente de Variação da análise da variância (ANOVA) de maçãs 'Royal Gala' submetidas a estresse inicial por baixo $\mathrm{O}_{2}$ /aplicação de 1-MCP, após sete meses de armazenamento em atmosfera controlada (AC), em $0,5^{\circ} \mathrm{C}$, mais sete dias de exposição a $20^{\circ} \mathrm{C}$. Santa Maria-RS, 2010

\begin{tabular}{lcccc}
\hline \multirow{2}{*}{ Variável } & \multicolumn{2}{c}{ F calculado } & CV $(\%)$ \\
\cline { 2 - 4 } & Estresse/1-MCP x AC* & Estresse/1-MCP & AC & 21,83 \\
\hline Podridões & $1,017^{\mathrm{ns}}$ & $4,292^{* *}$ & $2,814^{* *}$ & 21,59 \\
Degenerescência & $0,671^{\mathrm{ns}}$ & $2,507^{\mathrm{ns}}$ & $1,228^{\mathrm{ns}}$ & 20,43 \\
Polpa Farinácea & $0,576^{\mathrm{ns}}$ & $4,539^{* *}$ & $2,228^{\mathrm{ns}}$ & 10,03 \\
Frutos sadios & $0,669^{\mathrm{ns}}$ & $3,710^{* *}$ & $1,976^{\mathrm{ns}}$ & 4,11 \\
Firmeza de polpa & $0,768^{\mathrm{ns}}$ & $3,159^{* *}$ & $2,491^{\mathrm{ns}}$ & 3,60 \\
Acidez & $3,277^{* *}$ & $2,957^{* *}$ & $1,092^{\mathrm{ns}}$ & 30,05 \\
Atividade ACC oxidase & $1,821^{\mathrm{ns}}$ & $13,445^{* *}$ & $7,364^{* *}$ & 26,68 \\
Etileno - saída da câmara & $9,589^{* *}$ & $55,646^{* *}$ & $37,509^{* *}$ & $1,168^{\mathrm{ns}}$ \\
Etileno - 7 dias a $20{ }^{\circ} \mathrm{C}$ & $0,330^{\mathrm{ns}}$ & $0,917^{\mathrm{ns}}$ & 55,90 \\
\hline
\end{tabular}

*Atmosfera controlada; ${ }^{\text {ns }}$ não significativo a $5 \%$ de probabilidade de erro; ${ }^{* *}$ significativo a $5 \%$ de probabilidade de erro 
Tabela 2 - Ocorrência de podridões em maçã 'Royal Gala' após sete meses de armazenamento em atmosfera controlada, com ou sem aplicação de 1-MCP e com ou sem estresse inicial por baixo oxigênio, mais sete dias de exposição a $20^{\circ} \mathrm{C}$. Santa Maria-RS, 2010

\begin{tabular}{|c|c|c|c|c|c|}
\hline \multirow{3}{*}{$\mathrm{kPa}\left(\mathrm{O}_{2}+\mathrm{CO}_{2}\right)$} & \multicolumn{2}{|c|}{ Sem 1-MCP } & \multicolumn{2}{|c|}{ Com 1-MCP } & \multirow{3}{*}{ Média } \\
\hline & Sem estresse & Com estresse & Sem estresse & Com estresse & \\
\hline & \multicolumn{4}{|c|}{ 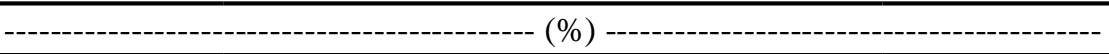 } & \\
\hline $1,2+2,0$ & 16,13 & 27,33 & 13,25 & 20,00 & $19,2 \mathrm{ab}^{*}$ \\
\hline $1,0+2,0$ & 7,96 & 24,17 & 13,00 & 23,00 & $17,0 \mathrm{~b}$ \\
\hline $0,8+1,0$ & 19,00 & 22,09 & 15,85 & 16,04 & $18,2 \mathrm{ab}$ \\
\hline $0,6+1,0$ & 18,00 & 25,00 & 16,67 & 20,25 & $20,0 \mathrm{ab}$ \\
\hline $0,5+1,0$ & 25,43 & 26,17 & 25,14 & 25,00 & $25,4 \mathrm{a}$ \\
\hline Média & $17,3 \mathrm{~B}$ & $24,9 \mathrm{~A}$ & $16,8 \mathrm{~B}$ & $20,9 \mathrm{AB}$ & \\
\hline
\end{tabular}

*Médias seguidas pela mesma letra, maiúscula na linha e minúscula na coluna, não diferem entre si pelo teste de Tukey $(p<0,05)$

Tabela 3 - Distúrbios fisiológicos em maçã 'Royal Gala' após sete meses de armazenamento em atmosfera controlada, com ou sem aplicação de 1-MCP e com ou sem estresse inicial por baixo oxigênio, mais sete dias de exposição a $20^{\circ} \mathrm{C}$. Santa Maria-RS, 2010

\begin{tabular}{|c|c|c|c|c|c|}
\hline \multirow{2}{*}{$\mathrm{kPa}\left(\mathrm{O}_{2}+\mathrm{CO}_{2}\right)$} & \multicolumn{2}{|c|}{ Sem 1-MCP } & \multicolumn{2}{|c|}{ Com 1-MCP } & \multirow[t]{2}{*}{ Média } \\
\hline & Sem estresse & Com estresse & Sem estresse & Com estresse & \\
\hline \multicolumn{6}{|c|}{---------------------------------------- Degenerescência de polpa $(\%)$} \\
\hline $1,2+2,0$ & 16,7 & 25,3 & 19,6 & 22,9 & $21,1 a^{*}$ \\
\hline $1,0+2,0$ & 20,8 & 22,6 & 18,3 & 27,0 & $22,2 \mathrm{a}$ \\
\hline $0,8+1,0$ & 13,3 & 22,3 & 17,8 & 14,8 & $17,1 \mathrm{a}$ \\
\hline $0,6+1,0$ & 16,3 & 20,3 & 17,9 & 18,8 & $18,3 \mathrm{a}$ \\
\hline $0,5+1,0$ & 17,6 & 21,4 & 11,0 & 24,8 & $18,7 \mathrm{a}$ \\
\hline Média & $16,9 \mathrm{~A}$ & $22,4 \mathrm{~A}$ & $16,9 \mathrm{~A}$ & $21,6 \mathrm{~A}$ & \\
\hline \multicolumn{6}{|c|}{ 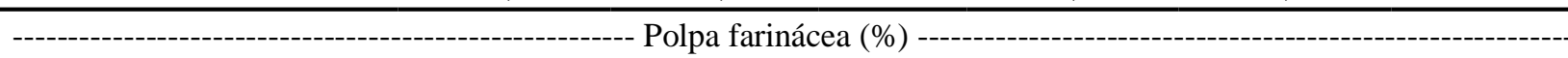 } \\
\hline $1,2+2,0$ & 16,7 & 29,6 & 23,7 & 24,0 & $23,5 \mathrm{a}$ \\
\hline $1,0+2,0$ & 23,7 & 28,8 & 20,4 & 31,0 & $26,0 \mathrm{a}$ \\
\hline $0,8+1,0$ & 18,4 & 27,1 & 17,8 & 17,1 & $20,1 \mathrm{a}$ \\
\hline $0,6+1,0$ & 14,2 & 23,4 & 18,9 & 17,8 & $18,6 \mathrm{a}$ \\
\hline $0,5+1,0$ & 18,6 & 26,6 & 14,3 & 23,6 & $20,8 \mathrm{a}$ \\
\hline Média & $18,3 \mathrm{~B}$ & $27,1 \mathrm{~A}$ & $19,0 \mathrm{~B}$ & $22,7 \mathrm{AB}$ & \\
\hline
\end{tabular}

*Médias seguidas pela mesma letra, maiúscula na linha e minúscula na coluna, não diferem entre si pelo teste de Tukey $(p<0,05)$

também foram eficientes no controle da produção de etileno, resultando em valores extremamente baixos e não havendo diferença entre eles após seis dias de exposição a $20^{\circ} \mathrm{C}$ (Tabela 7). Com relação à aplicação de estresse inicial por baixo $\mathrm{O}_{2}$, Wang e Dilley (2000) observaram em maçã 'Granny Smith' alta incidência de escurecimento interno em AC com 3,0 kPa de $\mathrm{O}_{2}$, que diminuiu pela metade com a aplicação de estresse inicial e posterior armazenamento em $3,0 \mathrm{kPa}$ de $\mathrm{O}_{2}$ e foi controlada completamente com estresse inicial e 1,5 kPa de $\mathrm{O}_{2}$. Possivelmente, não se observou esta diferença no presente trabalho, em função das pressões parciais de $\mathrm{O}_{2}$ utilizadas serem mais próximas entre si e menores (abaixo de 1,2 kPa) que aquelas utilizadas pelos autores citados acima.

As diferentes condições de AC testadas neste experimento não influenciaram a ocorrência de polpa farinácea dos frutos. Por outro lado, nos frutos submetidos a um estresse inicial por baixo oxigênio, houve um valor significativamente maior de polpa farinácea, principalmente para os frutos que não receberam tratamento com 1-MCP. Para os frutos 
com 1-MCP e aplicação de estresse inicial, também se observa alta ocorrência deste distúrbio, porém sem diferir significativamente das duas condições sem estresse (com e sem 1-MCP) (Tabela 3).

A ocorrência de polpa farinácea está relacionada com a força relativa que mantém a estrutura da parede celular em comparação com a força de ligação da lamela média. Quando a força de ligação que mantém unida uma célula à outra é menor que a força que mantém a integridade da parede celular de células individuais, ocorre a separação das células e estas células intactas dão a sensação de textura farinácea. Isto ocorre porque as moléculas de protopectina (pectina insolúvel) são transformadas em pectinas solúveis na lamela média, diminuindo a força de coesão entre as células (PRASANNA; PRABHA; THARANATHAN, 2007). Este distúrbio geralmente está associado com o avanço do amadurecimento dos frutos, sendo que a forma de armazenamento exerce grande influência. $\mathrm{O}$ armazenamento refrigerado de maçãs provoca o desenvolvimento mais rápido e em maior porcentagem de frutos com este distúrbio, comparado com AC ou armazenamento em condições de ultrabaixo $\mathrm{O}_{2}$ (BRACKMANN et al., 2005). No entanto, no presente trabalho foi constatado que nas condições de estresse inicial a ocorrência de polpa farinácea foi maior, provavelmente sendo uma condição excessiva de baixo oxigênio, que pode ter induzido a fermentação dos frutos, com grande produção de etanol e acetaldeído que, de alguma forma, induziram a maior ocorrência deste distúrbio nestes frutos. De acordo com Weber (2010), a aplicação de $0,5 \mathrm{~mL}$ de etanol $\mathrm{kg}^{-1}$ de fruto mês ${ }^{-1}$ nas câmaras de armazenamento de maçãs, aumentou a ocorrência de polpa farinácea, comparado com AC, aplicação de 1-MCP ou absorção de etileno.

A maior porcentagem de frutos sadios foi verificada nas duas condições sem estresse inicial por baixo oxigênio, no entanto, não diferiram significativamente da condição com estresse e aplicação de 1-MCP (Tabela 4). Fica evidente, a partir destes resultados, que tanto a aplicação de 1-MCP, quanto o estresse inicial por baixo oxigênio não foram eficientes em diminuir a ocorrência de distúrbios fisiológicos e podridões nos frutos e, em consequência disso, a porcentagem de frutos sadios foi menor nos tratamentos com estresse inicial por baixo $\mathrm{O}_{2}$.

De acordo com Saquet, Streif e Bangerth (2003), o baixo nível de energia, em função do armazenamento em condições com $\mathrm{O}_{2}$ muito baixo, é responsável pelo desenvolvimento de desordens fisiológicas nos frutos. Neste caso, também pode haver produção de etanol e acetaldeído que, em altas concentrações, aumentam a permeabilidade das membranas celulares, causando danos à bicamada lipídica, estando diretamente relacionada com a ocorrência de desordens (PODD; VAN STADEN, 1998). Outro fator que pode ter contribuído para a maior ocorrência de danos e menor porcentagem de frutos sadios nos frutos que receberam estresse inicial, verificado no presente trabalho, é o fato de estarem em estádio de maturação avançado na colheita. Lau (1997) também constatou que o estresse inicial não traz benefícios ao armazenamento de maçã 'Starkrimson Delicious' e observou um aumento de desordens em frutos colhidos com índice iodo-amido mais elevado (maturação avançada).

A firmeza de polpa é um dos atributos que mais é considerado pelos consumidores de maçãs. Apesar da baixa firmeza de polpa na colheita $(68,8 \mathrm{~N})$, todas as condições de armazenamento do presente trabalho foram eficientes em manter a firmeza em valores próximos ao observado na colheita (Tabela 5). Considerando as diferentes condições de $\mathrm{AC}$, o armazenamento em $0,6 \mathrm{kPa} \mathrm{O}+1,0 \mathrm{kPa} \mathrm{CO}_{2}$ proporcionou a menor perda de firmeza nos frutos, no entanto, diferindo significativamente apenas da condição com 1,0 kPa O$+2,0 \mathrm{kPa} \mathrm{CO}$. Por outro lado, a aplicação de 1-MCP e o estresse inicial por baixo oxigênio não

Tabela 4 - Porcentagem de frutos sadios de maçã 'Royal Gala' após sete meses de armazenamento em atmosfera controlada, com ou sem aplicação de 1-MCP e com ou sem estresse inicial por baixo oxigênio, mais sete dias de exposição a $20^{\circ} \mathrm{C}$. Santa Maria-RS, 2010

\begin{tabular}{|c|c|c|c|c|c|}
\hline \multirow{3}{*}{$\mathrm{kPa}\left(\mathrm{O}_{2}+\mathrm{CO}_{2}\right)$} & \multicolumn{2}{|c|}{ Sem 1-MCP } & \multicolumn{2}{|c|}{ Com 1-MCP } & \multirow{3}{*}{ Média } \\
\hline & Sem estresse & Com estresse & Sem estresse & Com estresse & \\
\hline & - & 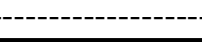 & & - & \\
\hline $1,2+2,0$ & 69,8 & 61,2 & 67,1 & 68,7 & $66,7 a^{*}$ \\
\hline $1,0+2,0$ & 71,3 & 64,0 & 71,5 & 59,0 & $66,4 \mathrm{a}$ \\
\hline $0,8+1,0$ & 71,4 & 60,9 & 74,2 & 76,5 & $70,7 \mathrm{a}$ \\
\hline $0,6+1,0$ & 71,5 & 64,5 & 71,7 & 70,8 & $69,6 \mathrm{a}$ \\
\hline $0,5+1,0$ & 61,6 & 57,0 & 68,2 & 63,7 & $62,6 \mathrm{a}$ \\
\hline Média & $69,1 \mathrm{~A}$ & $61,5 \mathrm{~B}$ & $70,5 \mathrm{~A}$ & $67,7 \mathrm{AB}$ & 67,2 \\
\hline
\end{tabular}

*Médias seguidas pela mesma letra, maiúscula na linha e minúscula na coluna, não diferem entre si pelo teste de Tukey $(p<0,05)$ 
Tabela 5 - Firmeza de polpa de maçãs 'Royal Gala' após sete meses de armazenamento em atmosfera controlada, com ou sem aplicação de 1-MCP e com ou sem estresse inicial por baixo oxigênio, mais sete dias de exposição a $20{ }^{\circ} \mathrm{C}$. Santa Maria-RS, 2010

\begin{tabular}{|c|c|c|c|c|c|}
\hline \multirow{3}{*}{$\mathrm{kPa}\left(\mathrm{O}_{2}+\mathrm{CO}_{2}\right)$} & \multicolumn{2}{|c|}{ Sem 1-MCP } & \multicolumn{2}{|c|}{ Com 1-MCP } & \multirow{3}{*}{ Média } \\
\hline & Sem estresse & Com estresse & Sem estresse & Com estresse & \\
\hline & \multicolumn{4}{|c|}{ רי- } & \\
\hline $1,2+2,0$ & 69,6 & 65,4 & 70,6 & 66,5 & $68,0 \mathrm{ab}^{*}$ \\
\hline $1,0+2,0$ & 67,6 & 64,8 & 68,7 & 65,0 & $66,5 \mathrm{~b}$ \\
\hline $0,8+1,0$ & 68,6 & 68,2 & 68,0 & 70,0 & $68,7 \mathrm{ab}$ \\
\hline $0,6+1,0$ & 69,9 & 68,8 & 69,8 & 69,2 & $69,4 \mathrm{a}$ \\
\hline $0,5+1,0$ & 69,8 & 68,0 & 69,6 & 67,4 & $68,7 \mathrm{ab}$ \\
\hline Média & $69,1 \mathrm{~A}$ & $67,0 \mathrm{~A}$ & $69,3 \mathrm{~A}$ & $67,6 \mathrm{~A}$ & 68,3 \\
\hline
\end{tabular}

*Médias seguidas pela mesma letra, maiúscula na linha e minúscula na coluna, não diferem entre si pelo teste de Tukey $(p<0,05)$

influenciaram na perda da firmeza de polpa. Pesis et al. (2010) constataram que um estresse inicial por baixo $\mathrm{O}_{2}$ (fluxo de $\mathrm{N}_{2}$ por 10 dias) foi eficiente em manter a firmeza de maçãs 'Granny Smith', com resultados similares à aplicação de 1-MCP, no entanto, estes autores utilizaram o armazenamento refrigerado após estresse inicial. Assim, no presente estudo, as baixas concentrações de $\mathrm{O}_{2}$ utilizadas para o armazenamento em AC, provavelmente foram eficientes em manter a firmeza dos frutos, com valores similares à aplicação de 1-MCP e estresse inicial.

Apesar de existirem relatos na literatura do efeito benéfico da aplicação de estresse inicial seguido do armazenamento em AC sobre a manutenção da firmeza de maçãs (MATTÈ et al., 2005; WANG; DILLEY, 2000), Lau (1997) verificou que o estresse inicial por baixo oxigênio não foi eficiente na manutenção da firmeza de maçãs 'StarkrimsonDelicious'quando seguido doarmazenamento em 0,7 ou $1,5 \mathrm{kPa}$ de $\mathrm{O}_{2}$. Este autor observou que quanto mais avançada a maturação na colheita, maior a perda de firmeza pelos frutos que receberam estresse inicial, comparado com aqueles que foram armazenados em AC apenas. Desta forma, o estádio de maturação mais avançado dos frutos utilizados no presente trabalho, também pode ser uma causa da ineficiência do estresse inicial sobre a manutenção da firmeza.

Na avaliação da acidez, para as diferentes condições de estresse inicial e 1-MCP, não se observa diferença entre as condições de $\mathrm{AC}$, enquanto que, dentro de cada condição de $\mathrm{AC}$, apenas em 1,2 $\mathrm{kPa}$ de $\mathrm{O}_{2}+2,0 \mathrm{kPa}$ de $\mathrm{CO}_{2}$ ocorre diferença entre os tratamentos (Tabela 6). Nesta condição, a aplicação de 1-MCP e sem estresse inicial proporcionou maior manutenção da acidez, no entanto diferindo significativamente apenas da condição sem 1-MCP e com estresse. Este fato evidencia um efeito benéfico do 1-MCP sobre a manutenção da acidez, especialmente em condições de armazenamento com $\mathrm{O}_{2}$ mais alto, perdendo este efeito à medida que a concentração de $\mathrm{O}_{2}$ vai diminuindo. Ao contrário de Mattè et al. (2005), que observaram maior

Tabela 6 - Acidez da maçã 'Royal Gala' após sete meses de armazenamento em atmosfera controlada, com ou sem aplicação de 1-MCP e com ou sem estresse inicial por baixo oxigênio, mais sete dias de exposição a $20^{\circ} \mathrm{C}$. Santa Maria-RS, 2010

\begin{tabular}{llllll}
\hline \multirow{2}{*}{$\mathrm{kPa}\left(\mathrm{O}_{2}+\mathrm{CO}_{2}\right)$} & \multicolumn{2}{c}{ Sem 1-MCP } & \multicolumn{2}{c}{ Com 1-MCP } & \multirow{2}{*}{ Média } \\
\cline { 2 - 4 } & \multicolumn{1}{c}{ Sem estresse } & Com estresse & Sem estresse & Com estresse & \\
\cline { 2 - 4 } & $-3,78 \mathrm{ABa}^{*}$ & $3,48 \mathrm{Ba}$ & $3,90 \mathrm{Aa}$ & $3,62 \mathrm{ABa}$ & 3,69 \\
$1,2+2,0$ & $3,58 \mathrm{Aa}$ & $3,72 \mathrm{Aa}$ & $3,60 \mathrm{Aa}$ & $3,70 \mathrm{Aa}$ & 3,65 \\
$0,0+2,0$ & $3,68 \mathrm{Aa}$ & $3,62 \mathrm{Aa}$ & $3,68 \mathrm{Aa}$ & $3,92 \mathrm{Aa}$ & 3,73 \\
$0,6+1,0$ & $3,82 \mathrm{Aa}$ & $3,70 \mathrm{Aa}$ & $3,62 \mathrm{Aa}$ & $3,75 \mathrm{Aa}$ & 3,73 \\
$0,5+1,0$ & $3,62 \mathrm{Aa}$ & $3,58 \mathrm{Aa}$ & $3,75 \mathrm{Aa}$ & $3,70 \mathrm{Aa}$ & 3,66 \\
Média & 3,70 & 3,62 & 3,71 & 3,74 & \\
\hline
\end{tabular}

*Médias seguidas pela mesma letra, maiúscula na linha e minúscula na coluna, não diferem entre si pelo teste de Tukey $(p<0,05)$ 
conteúdo de ácido málico em frutos armazenados em estresse inicial seguido de ultrabaixo $\mathrm{O}_{2}$, no presente trabalho não foi evidenciado benefícios da aplicação de estresse inicial por baixo oxigênio sobre a manutenção da acidez. Resultado semelhante foi constatado por Zanella (2003), que observou maior acidez em frutos tratados com 1-MCP, sendo que o armazenamento em estresse inicial não afetou este parâmetro. A aplicação de 1-MCP atrasa a degradação dos ácidos orgânicos resultando em maiores níveis de acidez titulável, especialmente após um período de vida de prateleira dos frutos (ZANELLA et al., 2005).

$\mathrm{O}$ armazenamento em menores pressões parciais de $\mathrm{O}_{2}$ e $\mathrm{CO}_{2}$ proporciona significativa diminuição da atividade da enzima ACC oxidase (Tabela 7). Na rota de produção de etileno, a conversão de ACC (Ácido 1-aminociclopropano-1-carboxílico) em etileno requer, além da enzima ACC oxidase, a presença de $\mathrm{O}_{2}$ (YANG; HOFFMAN, 1984). Portanto, as baixas pressões parciais de $\mathrm{O}_{2}$ utilizadas no presente trabalho limitaram a disponibilidade de oxigênio, diminuindo a atividade desta enzima. Além disso, o baixo $\mathrm{O}_{2}$ pode interferir na expressão gênica da enzima ACC oxidase. Lara et al. (2011) verificaram baixos níveis de transcritos desta enzima ( $P p A C O 1)$ em pêssego que estiveram sob anoxia durante 72 horas.

Com relação à aplicação de estresse inicial por baixo oxigênio, este procedimento não influenciou a atividade da enzima ACC oxidase, enquanto que a aplicação de 1-MCP nos frutos diminui a atividade da mesma, corroborando com Brackmann et al. (2009), que constataram a diminuição da atividade desta enzima com a aplicação de 1-MCP.

$\mathrm{Na}$ avaliação da produção de etileno, no momento da abertura das câmaras, novamente não se observa efeito da aplicação de estresse inicial por baixo $\mathrm{O}_{2}$. A aplicação de 1-MCP reduziu a produção de etileno, mas este fato é observado principalmente em AC com 1,2 e 1,0 $\mathrm{kPa} \mathrm{O}_{2}$. Nas menores pressões parciais de $\mathrm{O}_{2}$ não houve diferença entre a produção de etileno para frutos tratados ou não com 1-MCP (Tabela 8). Quanto às diferentes condições de $\mathrm{AC}$ utilizadas, nos frutos que receberam 1-MCP não houve diferença entre os tratamentos, sendo que em todas as condições ocorreu baixa produção de etileno. Contrariamente, para os frutos sem 1-MCP, nas menores pressões parciais de $\mathrm{O}_{2}$, houve menor produção de etileno. Possivelmente, esta condição tenha proporcionado um início de processo fermentativo, com pequena produção de etanol e acetaldeído, que afeta a atividade e expressão gênica das enzimas ACC sintase e ACC oxidase (ASODA et al., 2009), diminuindo a produção de etileno, em comparação com as condições de AC com concentrações maiores de $\mathrm{O}_{2}$. Além disso, a enzima ACC oxidase necessita de $\mathrm{O}_{2}$ para conversão de ACC a etileno (YANG; HOFFMAN, 1984). Este resultado evidencia que as baixas pressões parciais de $\mathrm{O}_{2}$ durante $\mathrm{o}$ armazenamento são eficientes em inibir a produção de etileno de forma semelhante à aplicação de 1-MCP. Já na análise aos sete dias de exposição a $20^{\circ} \mathrm{C}$, não foi verificada diferença entre os tratamentos para a produção de etileno (Tabela 8).

A partir da análise dos dados percebe-se que a aplicação de estresse inicial, em maçãs 'Royal Gala', não trouxe os benefícios esperados e relatados em alguns trabalhos na literatura. O tempo de duração de estresse, bem como a temperatura e a pressão parcial de $\mathrm{O}_{2}$ durante o posterior armazenamento em AC, são importantes fatores que determinam a eficácia do tratamento (WANG; DILLEY, 2000). A colheita em estádio de maturação mais avançado também afeta a qualidade dos frutos que recebem estresse inicial por baixo $\mathrm{O}_{2}$ (LAU, 1997).

Tabela 7 - Atividade da enzima ACC oxidase em maçãs 'Royal Gala' após sete meses de armazenamento em atmosfera controlada, com ou sem aplicação de 1-MCP e com ou sem estresse inicial por baixo oxigênio, mais sete dias de exposição a $20{ }^{\circ} \mathrm{C}$. Santa Maria-RS, 2010

\begin{tabular}{|c|c|c|c|c|c|}
\hline \multirow{3}{*}{$\mathrm{kPa}\left(\mathrm{O}_{2}+\mathrm{CO}_{2}\right)$} & \multicolumn{2}{|c|}{ Sem 1-MCP } & \multicolumn{2}{|c|}{ Com 1-MCP } & \multirow{3}{*}{ Média } \\
\hline & Sem estresse & Com estresse & Sem estresse & Com estresse & \\
\hline & \multicolumn{4}{|c|}{${ }^{-1}{ }_{2} \mathrm{H}_{4} \mathrm{~g}^{-1} \mathrm{~h}^{-1}{ }^{-}$} & \\
\hline $1,2+2,0$ & $32,3^{*}$ & 53,0 & 20,9 & 26,5 & $33,2 \mathrm{ab}$ \\
\hline $1,0+2,0$ & 40,2 & 39,6 & 25,9 & 41,3 & $35,6 \mathrm{a}$ \\
\hline $0,8+1,0$ & 29,3 & 35,9 & 17,5 & 23,1 & $26,4 \mathrm{bc}$ \\
\hline $0,6+1,0$ & 28,9 & 25,5 & 12,7 & 19,4 & $22,2 \mathrm{c}$ \\
\hline $0,5+1,0$ & 34,0 & 21,8 & 19,3 & 23,7 & $24,0 \mathrm{c}$ \\
\hline Média & $32,9 \mathrm{~A}$ & $35,7 \mathrm{~A}$ & $19,6 \mathrm{~B}$ & $24,3 \mathrm{~B}$ & \\
\hline
\end{tabular}

*Médias seguidas pela mesma letra, maiúscula na linha e minúscula na coluna, não diferem entre si pelo teste de Tukey $(p<0,05)$ 
Tabela 8 - Produção de etileno em maçãs 'Royal Gala' após sete meses de armazenamento em atmosfera controlada, com ou sem aplicação de 1-MCP e com ou sem estresse inicial por baixo oxigênio, e após sete dias de exposição a $20{ }^{\circ} \mathrm{C}$. Santa Maria-RS, 2010

\begin{tabular}{|c|c|c|c|c|c|}
\hline \multirow{2}{*}{$\mathrm{kPa}\left(\mathrm{O}_{2}+\mathrm{CO}_{2}\right)$} & \multicolumn{2}{|c|}{ Sem 1-MCP } & \multicolumn{2}{|c|}{ Com 1-MCP } & \multirow{2}{*}{ Média } \\
\hline & Sem estresse & Com estresse & Sem estresse & Com estresse & \\
\hline \multicolumn{6}{|c|}{ - Saída da câmara $\left(\mu \mathrm{L} \mathrm{C}_{2} \mathrm{H}_{4} \mathrm{~kg}^{-1} \mathrm{~h}^{-1}\right)$ - } \\
\hline $1,2+2,0$ & $0,140 \mathrm{ABbc}^{*}$ & $0,184 \mathrm{Aa}$ & $0,076 \mathrm{BCa}$ & $0,063 \mathrm{Ca}$ & 0,166 \\
\hline $1,0+2,0$ & $0,261 \mathrm{Aa}$ & $0,166 \mathrm{Bab}$ & $0,048 \mathrm{Ca}$ & $0,100 \mathrm{BCa}$ & 0,144 \\
\hline $0,8+1,0$ & $0,177 \mathrm{Ab}$ & $0,107 \mathrm{Bbc}$ & $0,053 \mathrm{Ba}$ & $0,068 \mathrm{Ba}$ & 0,101 \\
\hline $0,6+1,0$ & $0,061 \mathrm{Ad}$ & $0,054 \mathrm{Ac}$ & $0,037 \mathrm{Aa}$ & $0,041 \mathrm{Aa}$ & 0,048 \\
\hline $0,5+1,0$ & 0,077 Acd & $0,068 \mathrm{Ac}$ & $0,050 \mathrm{Aa}$ & $0,063 \mathrm{Aa}$ & 0,064 \\
\hline Média & 0,143 & 0,166 & 0,053 & 0,067 & \\
\hline \multicolumn{6}{|c|}{ - } \\
\hline $1,2+2,0$ & 0,093 & 0,061 & 0,065 & 0,093 & $0,078 \mathrm{a}$ \\
\hline $1,0+2,0$ & 0,071 & 0,061 & 0,082 & 0,064 & $0,070 \mathrm{a}$ \\
\hline $0,8+1,0$ & 0,082 & 0,050 & 0,055 & 0,055 & $0,060 \mathrm{a}$ \\
\hline $0,6+1,0$ & 0,062 & 0,050 & 0,046 & 0,048 & $0,052 \mathrm{a}$ \\
\hline $0,5+1,0$ & 0,059 & 0,050 & 0,074 & 0,055 & $0,061 \mathrm{a}$ \\
\hline Média & $0,073 \mathrm{~A}$ & $0,054 \mathrm{~A}$ & $0,066 \mathrm{~A}$ & $0,063 \mathrm{~A}$ & \\
\hline
\end{tabular}

*Médias seguidas pela mesma letra, maiúscula na linha e minúscula na coluna, não diferem entre si pelo teste de Tukey $(p<0,05)$

\section{CONCLUSÕES}

1.0 estresse inicial por baixo oxigênio não foi eficiente em manter a qualidade de maçãs 'Royal Gala', inclusive aumentando a ocorrência de distúrbios fisiológicos e podridões nos frutos após o armazenamento;

2. As condições de AC, na faixa testada no presente trabalho, apresentaram um padrão bastante próximo nos parâmetros de maturação e qualidade dos frutos;

3. Apesar de manter menor a atividade da enzima ACC oxidase, a aplicação de 1-MCP não melhora a conservação da qualidade de maçãs 'Royal Gala' armazenadas em ultrabaixo $\mathrm{O}_{2}$, como verificado nas menores pressões parciais $(<1,0 \mathrm{kPa})$ utilizadas no presente trabalho.

\section{REFERÊNCIAS}

AMARANTE, C. V. T.; STEFFENS, C. A.; ARGENTA, L. C. Yield and fruit quality of 'Gala' and 'Fuji' apple trees protected by white anti-hail net. Scientia Horticulturae, v. 129, n. 1, p. 79-85, 2011.

ASODA, T. et al. Effects of postharvest etanol vapor treatment on ethylene responsiveness in broccoli. Postharvest Biology and Technology, v. 52, n. 2, p. 216-220, 2009.
BLANKENSHIP, S. M.; DOLE, J. M. 1-Methylcyclopropene: a review. Postharvest Biology and Technology, v. 28, n. 1, p. 1-25, 2003.

BRACKMANN, A. et al. Conseqüência da umidade relativa durante o armazenamento refrigerado e em atmosfera controlada na qualidade da maçã 'Gala'. Ciência Rural, v. 35, n. 5, p. 1196-1200, 2005.

BRACKMANN, A. et al. Manutenção da qualidade póscolheita de maçãs 'Royal Gala' e 'Galaxy' sob armazenamento em atmosfera controlada. Ciência Rural, v. 38, n. 9, p. 24782484, 2008.

BRACKMANN, A. et al. Manejo do etileno e sua relação com a maturação da maçãs 'Gala' armazenada em atmosfera controlada. Bragantia, v. 68, n. 2, p. 519-525, 2009.

BUFLER, G. Ethylene-promoted conversion of 1aminocyclopropene-1-carboxylic acid to ethylene in peel of apple at various stages of fruit development. Plant Physiology, v. 80, n. 2, p. 539-543, 1986.

CAMILO, A. P.; DENARDI, F. Cultivares: Descrição e comportamento no Sul do Brasil. In: EPAGRI. A cultura da macieira. Florianópolis: Empresa de Pesquisa Agropecuária e Extensão Rural de Santa Catarina, 2006. cap. 5, p. 113-168.

DELONG, J. M.; PRANGE, R. K.; HARRISON, P. A. The influence of 1-methyl-cyclopropene on 'Cortland' and 'Mc Intosh' apple quality following long-term storage. HortScience, v. 39, n. 5, p. 1062-1065, 2004. 
EKMAN, J. H.; GOLDING, J. B.; McGLASSON, W. B. Innovation in cold storage technologies. Stewart Postharvest Review, v. 1, n. 3, p. 1-14, 2005.

FALLIK, E. et al. A 24-h anoxia treatment reduces decay development while maintaining tomato fruit quality. Postharvest Biology and Technology, v. 29, n. 2, p. 233236, 2003.

LARA, M. V. et al. Peach (Prunus persica) fruit response to anoxia: reversible ripening delay and biochemical changes. Plant Cell Physiology, v. 52, n. 2, p. 392-403, 2011.

LAU, O. L. Initial low oxygen stress offers no scald control benefits to 'Starkrimson Delicious' apples in $0.7 \mathrm{kPa} \mathrm{O}_{2}$ storage. Hort Science, v. 32, n. 7, p. 1239-1241, 1997.

MATTÈ, P. et al. ILOS + ULO as a practical technology for apple scald prevention. Acta Horticulturae, v. 682, p. 15431550, 2005.

PESIS, E. et al. Short anaerobiosis period prior to cold storage alleviates bitter pit and superficial scald in Granny Smith apples. Journal of the Science of Food and Agriculture, v. 90, n. 12, p. 2114-2123, 2010.

PODD, L. A.; VAN STADEN, J. The role of ethanol and acetaldehyde in flower senescence and fruit ripening - a review. Plant growth regulation, v. 26, n. 3, p. 183-189, 1998.

POLENTA, G.; BUDDE, C.; MURRAY, R. Effect of different pre-storage anoxic treatments on ethanol and acetaldehyde content in peaches. Postharvest Biology and Technology, v. 38, n. 3, p. 247-253, 2005.

PRASANNA, V.; PRABHA, T. N.; THARANATHAN, R. N. Fruit Ripening Phenomena-An Overview. Critical Reviews in Food Science and Nutrition, v. 47, n. 1, p. 1-19, 2007.
SAQUET, A. A.; STREIF, J.; BANGERTH, F. Energy metabolism and membrane lipid alterations in relation of brown heart development in 'Conference' pears during delayed controlled atmosphere storage. Postharvest Biology and Technology, v. 30, n. 2, p. 123-132, 2003.

TOEBE, M. et al. Dimensionamento amostral para avaliar firmeza da polpa e cor da epiderme em pêssego e maçã. Revista Ciência Agronômica, v. 42, n. 4, p. 1026-1035, 2011.

WANG, Z.; DILLEY, D. R. Initial low oxygen stress controls superficial scald of apples. Postharvest Biology and Technology, v. 18, n. 3, p. 201-213, 2000.

WATKINS, C. B. Storage disorders of controlled atmospherestored Empire apples. New York Fruit Quarterly, v. 18, n. 3, p.19-22, 2010.

WEBER, A. Aplicação de produtos da fermentação e ultrabaixo oxigênio para conservação de maçãs 'Royal Gala' . 2010. 89 f. Dissertação (Mestrado em Agronomia) - Centro de Ciências Rurais, Universidade Federal de Santa Maria, Santa Maria, 2010.

YANG, S. F.; HOFFMAN, N. E. Ethylene biosynthesis and its regulation in higher plants. Annual Review of Plant Physiology, v. 35 , p. $155-189,1984$.

ZANELLA, A. Control of apple superficial scald and ripening - a comparison between 1-methylcyclopropene and diphenylamine postharvest treatments, initial low oxygen stress and ultralow oxygen storage. Postharvest Biology and Technology, v. 27, n. 1, p. 69-78, 2003.

ZANELLA, A. et al. Fruit fluorescence response to low oxygen stress: modern storage technologies compared to 1-MCP treatment of apple. Acta Horticulturae, v. 682, p. 1535-1542, 2005 . 